\title{
Lattice dynamics and phase transitions in $\mathrm{Sn}_{2} \mathrm{P}_{2} \mathrm{~S}(\mathrm{Se})_{6}$ ferroelectric crystals
}

\author{
R.M.Yevych, Yu.M.Vysochanskii \\ Institute for Solid State Physics and Chemistry, Uzhgorod University, \\ Pidgirna Str., 46, Uzhgorod, 88000, Ukraine
}

Received August 3, 2005, in final form October 31, 2005

\begin{abstract}
Polarizable ion model was used in describing the lattice dynamics in the $\mathrm{Sn}_{2} \mathrm{P}_{2} \mathrm{~S}_{6}$ and $\mathrm{Sn}_{2} \mathrm{P}_{2} \mathrm{Se}_{6}$ ferroelectric crystals and their solid solutions. There has been obtained a good agreement of the calculated phonon spectra with the experimental data of Raman and Brillouin spectroscopies, neutron scattering and ultrasound experiments. Paraelectric phase instability has been modelled by negative charge transferring from the tin cations to the chalcogen ions, and by increasing the polarizabilities of the latter. The ferroelectric phase has been stabilized by tin atom displacement from centrosymmetric positions and a partial reversal recharging between tin and chalcogen ions. The effective charges decreasing by moving from $\mathrm{Sn}_{2} \mathrm{P}_{2} \mathrm{~S}_{6}$ to $\mathrm{Sn}_{2} \mathrm{P}_{2} \mathrm{Se}_{6}$ compounds determine the shift of condensation wave vector of soft optic phonons in paraelectric phase from $q=0$ in sulfur compound to $q>0$ in selenium compound. Such a change of dynamical instability character is connected with the appearance of incommensurate phase in $\mathrm{Sn}_{2} \mathrm{P}_{2}\left(\mathrm{Se}_{x} \mathrm{~S}_{1-x}\right)_{6}$ solid solution under $x>0.28$. The "two-mode" instability emerged as possible in the vicinity of Lifshitz point - there have been modelled the condensation of soft optic mode with $q \approx 0$ and mixed optic and transversal acoustic phonons near $q>0$. This fact requires further experimental and theoretical investigations.
\end{abstract}

Key words: lattice dynamics, polarizible ions model, ferroelectric phase transitions, incommensurate phase

PACS: $63.20 . \mathrm{Dj}, 77.80 . \mathrm{Bh}$

\section{Introduction}

$\mathrm{Sn}_{2} \mathrm{P}_{2} \mathrm{~S}(\mathrm{Se})_{6}$ crystals and their solid solutions present highly interesting investigation objects for the physics of structural phase transitions - they are uniaxial ferroelectrics with Lifshitz point and a tricritical point in the phase diagram [1,2]. For the $\mathrm{Sn}_{2} \mathrm{P}_{2} \mathrm{Se}_{6}$ crystals the sequence of phase transitions $(\mathrm{PT})$ of the second order from the paraelectric $(\mathrm{PE})$ phase to the IC phase under temperature $T_{i}=221 \mathrm{~K}$ and $\mathrm{PT}$ of the first order (lock-in transition) from the incommensurate (IC) phase to the ferroelectric $(\mathrm{FE})$ phase under temperature $T_{\mathrm{c}}=193 \mathrm{~K}$ with a wave vector of polarization modulation in the IC phase near the Brillouin zone (BZ) centre $-q_{i} \approx 0.1 q_{\max }\left(q_{\max }\right.$ corresponds to the BZ boundary) is realized. In the $\mathrm{Sn}_{2} \mathrm{P}_{2} \mathrm{~S}_{6}$ crystals under temperature $T_{0}=$ $337 \mathrm{~K}$ the second order PT from PE phase to FE phase is directly effected. The thermodynamic description of PT and the property anomalies of these ferroelectrics are given in [3,4] in the mean field approximation and with taking into account the higher harmonics of polarization modulations in the IC phase. PT from IC into the FE phase are more adequately described under the assumption of the possible presence of the modulating wave subharmonics [5]. There exists a rather good agreement with the experimental data concerning the form of $\mathrm{Sn}_{2} \mathrm{P}_{2}\left(\mathrm{Se}_{x} \mathrm{~S}_{1-x}\right)_{6}$ solid solutions phase diagram, the temperature and concentration dependence of dielectric susceptibility, heat capacity, wave vector modulation in the IC phase which has been reached in DIFFOUR model [6].

The dynamic properties of these crystals have been under consideration in a series of experimental works [7-12]. In [13], in particular, it has been shown that PT in $\mathrm{Sn}_{2} \mathrm{P}_{2} \mathrm{~S}_{6}$ lies in the crossover region from the "displacement" type to the "order-disorder" type. The comparison of the data on the lattice dynamics and the thermodynamic properties of $\mathrm{Sn}_{2} \mathrm{P}_{2} \mathrm{~S}_{6}$ and $\mathrm{Sn}_{2} \mathrm{P}_{2} \mathrm{Se}_{6}$ crystals has enabled 
one to make an assumption [14], that PT in the selenium compounds may be to a greater degree characterized as being of the "order-disorder" type. The molecular dynamic calculations have given a general phase diagram of $\mathrm{Sn}_{2} \mathrm{P}_{2}\left(\mathrm{Se}_{x} \mathrm{~S}_{1-x}\right)_{6}$ solid solutions in the Izing dipole model with some amendment for the short range interactions [15]. But in general the fluctuation spectrum of PT order parameter includes soft optic phonons interacting with some relaxation excitations. The investigation of the Raman scattering (RS) spectra [7,16,17] and the Brillouin scattering (BS) spectra [8] and neutron scattering $[9,10]$ have shown that side by side with the soft optic mode, characteristic of the PT "displacement" type, while approaching the PT temperature there may be observed an intensity increase of the central peak which is characteristic of the "order-disorder" PT type.

The $\mathrm{Sn}_{2} \mathrm{P}_{2} \mathrm{~S}(\mathrm{Se})_{6}$ crystals lattice dynamics has been previously considered in the rigid ion model $[18,19]$ within the assumption about the absence of deformations of $\left[\mathrm{P}_{2} \mathrm{~S}(\mathrm{Se})_{6}\right]^{4-}$ anion complexes forming the frame within which $\mathrm{Sn}^{2+}$ cations are placed. However, in the rigid ions approximation there have been differences as regards the experimental data concerning the unstable optic mode symmetry of the PE phase of $\mathrm{Sn}_{2} \mathrm{P}_{2} \mathrm{~S}_{6}$ and $\mathrm{Sn}_{2} \mathrm{P}_{2} \mathrm{Se}_{6}$ crystals as well as wave vector modulation orientation of the unstable mode under PT from the PE phase into the IC phase of the $\mathrm{Sn}_{2} \mathrm{P}_{2} \mathrm{Se}_{6}$ crystal. Later on the rigid ions model has been modified by also taking into account the anion complexes internal oscillations as well as sulfur atoms polarizability [20]. The potential of interaction between the atoms used in this work is rather complicated (there have been used different energy potential models in the consideration of internal and external oscillations), and therefore it has been impossible to take into account the static equilibrium conditions for the unit cell. However, taking into consideration only the polarizability of sulfur atoms has made it possible to achieve an agreement with the experimental data concerning the soft optic mode in the $\mathrm{Sn}_{2} \mathrm{P}_{2} \mathrm{~S}_{6}$ crystal FE phase. However, in [20], there has not been done any modelling of lattice instability in the PE phase of this crystal.

Let us note that the crystals under consideration are referred to the monoclinic syngony with a change in their symmetry under PT $P 2_{1} / c \rightarrow P c$. They are uniaxial ferroelectrics. In the FE phase the spontaneous polarization vector lies in the symmetry plane, which causes its fluctuations in amplitude as well as in orientation angle. A similar situation takes place for the wave vector modulation in the IC phase - it also lies in the monoclinic plane of symmetry. The given facts allow us to admit the possible presence of the longitudinal component in the polarization wave in its IC phase. While choosing the elementary cell in accordance with [21], the [100] and [001] axes are orientated at approximately the angle of $91.16^{\circ}$ (for $\mathrm{Sn}_{2} \mathrm{P}_{2} \mathrm{~S}_{6}$ under $300 \mathrm{~K}$ ), the spontaneous polarization vector in the symmetry plane is declined from the [100] axis at approximately $15^{\circ}$ [22] while the modulation vector in the IC phase of $\mathrm{Sn}_{2} \mathrm{P}_{2} \mathrm{Se}_{6}$ is declined in the symmetry plane at approximately $9^{\circ}$ in relation to the [001] axis [23]. Thus, the modulation wave of $\mathrm{Sn}_{2} \mathrm{P}_{2} \mathrm{Se}_{6}$ in its IC phase is likely to be close to the transversal, but symmetrically it may have a longitudinal component varying under the temperature or chemical composition changes in solid solutions.

In [24] there has been pointed out the presence of a new universality class for the critical behavior of the uniaxial ferroelectrics in the vicinity of the Lifshitz point (LP) and in the vicinity of the tricritical Lifshitz point. The experimental data for $\mathrm{Sn}_{2} \mathrm{P}_{2} \mathrm{~S}_{6}$ concerning the anomalous behavior of dielectric susceptibility [25], sound velocities [26], birefringence [27], diffuse scattering of X-rays [28] are generally well described in accordance with the predictions in [24] for the dipole Lifshitz point which is close to the tricritical point: the merging of these points preconditions a new universality class - the dipole tricritical Lifshitz point. However, the renormalization group description [24] is based on the uniaxial ferroelectric model of orthorhombic syngony - for this case the modulation wave in its IC phase is exactly transversal. Thus, there arises a great interest in the order parameter fluctuation spectrum in the vicinity of LP for the uniaxial ferroelectrics with the polarization and modulation wave vector in the monoclinic symmetry plane.

Besides, $\mathrm{Sn}_{2} \mathrm{P}_{2} \mathrm{~S}(\mathrm{Se})_{6}$ crystals possess semiconductor properties. In $\mathrm{Sn}_{2} \mathrm{P}_{2} \mathrm{~S}_{6}$ there have been observed the long-term relaxation effects of dielectric and ultrasonic properties [29,30]. It has been established that after a long-hour temperature stabilization in the PE phase close to the transition temperature one may observe splitting of the second order PT from the PE phase to the FE phase into two transitions - of the second and the first order, which in all likelihood, limit the 
IC phase. It has been assumed [29] that the pointed out relaxation effects are preconditioned by a slow establishment of equilibrium distribution of charge carriers in the impurity levels in the dielectric-semiconductor.

Obviously, electron-phonon interaction plays an important role in the mechanisms of structural transitions in $\mathrm{Sn}_{2} \mathrm{P}_{2} \mathrm{~S}(\mathrm{Se})_{6}$ crystals. The data concerning the kinetic properties of the above given materials also testify to its importance: the electroconductivity displays an irregular character inherent to polaron mechanisms [31]; heat conductivity is extremely low, characteristic of glasses in its magnitude, which points to the presence of specific effective mechanisms of scattering of the heatconducting phonons [32].

The given sum total of the properties (the dynamics relaxation component of the PT order parameter, the effect of the long-hour electronic relaxation on the transition character, i.e. LP coordinates, the polaron peculiarities manifestation in the kinetic properties) testifies to the probably essential connection of the polarization fluctuation with the ions charged state in $\mathrm{Sn}_{2} \mathrm{P}_{2} \mathrm{~S}(\mathrm{Se})_{6}$ crystals. Their structure is ion-covalent with two formula units in the elementary cell and nominal chargers of $\mathrm{Sn}^{2+}$ cations and $\left[\mathrm{P}_{2} \mathrm{~S}(\mathrm{Se})_{6}\right]^{4-}$ anions $[21,33]$. It is possible to assume that under heat displacements of the tin atom sublattice in relation to the quasimolecular complex sublattice and relative displacement of these structural groups as well as their deformations (the pointed out atom displacements in the elementary cell are evidently components of the spontaneous polarization which appears in the FE phase) there also takes place a recharging of ions. A significant role of the lone electron pair in the tin atoms for the description of $\mathrm{Sn}_{2} \mathrm{P}_{2} \mathrm{~S}_{6}$ crystal type properties has been marked in [34]. The ab initio calculations of the electron energy spectrum of $\mathrm{Sn}_{2} \mathrm{P}_{2} \mathrm{~S}_{6}$ crystals [35] and $\mathrm{Sn}_{2} \mathrm{P}_{2} \mathrm{Se}_{6}$ [36] indicate the difference of the tin ions charged state from +2 and, correspondingly, the difference of $\left[\mathrm{P}_{2} \mathrm{~S}(\mathrm{Se})_{6}\right]$ structural groups from the nominal charged state. The calculations [37] in the functional electron density approximation have shown that in the $\mathrm{Sn}_{2} \mathrm{P}_{2} \mathrm{~S}_{6}$ crystal under transition from the $\mathrm{PE}$ phase into the $\mathrm{FE}$ phase alongside with tin atom displacements there takes place an essential change of the electronic density spatial distribution in the environment of these atoms as well as there occurs a change in their charge state.

Thus, the given experimental data and the first principle calculation results testify to the essential limitation of rigid ions approximation for the description of lattice dynamics in $\mathrm{Sn}_{2} \mathrm{P}_{2} \mathrm{~S}_{6}$ type crystals. There have been described different approximations in literature considering the ion polarizability $[38,39]$. We have applied the simplest of such models given in [38].

In our work we made a calculation of the phonon spectra of the $\mathrm{Sn}_{2} \mathrm{P}_{2} \mathrm{~S}_{6}$ crystal PE and FE phases, traced the phonon spectrum change in the PE phase under transition from $\mathrm{Sn}_{2} \mathrm{P}_{2} \mathrm{~S}_{6}$ to $\mathrm{Sn}_{2} \mathrm{P}_{2} \mathrm{Se}_{6}$, modelled the optic mode instability in the PE phase of the crystals under investigation, considered a phonon spectrum change under the spontaneous polarization emergence in the $\mathrm{Sn}_{2} \mathrm{P}_{2} \mathrm{~S}_{6} \mathrm{FE}$ phase, analyzed the peculiarities of interatomic interactions determining the form of the soft optic branch, i.e. the space dispersion for the order parameter fluctuation rigidity, examined the concentration reconstruction of the $\mathrm{Sn}_{2} \mathrm{P}_{2}\left(\mathrm{Se}_{x} \mathrm{~S}_{1-x}\right)_{6}$ solid solutions phonon spectrum in the average crystal approximation, defined the specific character of the soft optic mode concentration dependence in the LP vicinity, particularly the LO-TO splitting, the specific role of this polar oscillation determining the two-mode character of the space dispersion concentration transformation for the order parameter fluctuation rigidity in the LP vicinity in monoclinic crystals.

\section{Methods}

The phonon spectrum calculations have been realized within the polarizable ion model in accordance with [38].

In the calculations there have been used the structural data for $\mathrm{Sn}_{2} \mathrm{P}_{2} \mathrm{~S}_{6}$ crystals (in the PE $(T=383 \mathrm{~K})$ and $\mathrm{FE}(T=293 \mathrm{~K})$ phases) and $\mathrm{Sn}_{2} \mathrm{P}_{2} \mathrm{Se}_{6}$ crystals (in the PE $(T=293 \mathrm{~K})$ phase) taken from $[21,33,40]$ works. The crystals under research are referred to ion-covalent compounds. The elementary cell contains two formula units. Figure 1, for instance, shows the $\mathrm{Sn}_{2} \mathrm{P}_{2} \mathrm{~S}_{6}$ crystal structure projection on the (010) symmetry plane. It is seen that the crystal lattice is formed by 
the $\mathrm{P}_{2} \mathrm{~S}_{6}$ molecular complexes frame connected by means of tin ions. The chemical bonds within the complexes are predominantly covalent, while between the anion complexes and cations they are the ion ones.

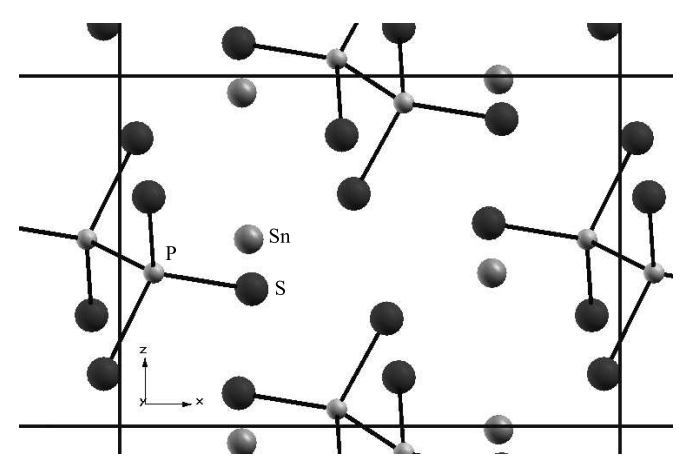

Figure 1. The crystal structure of $\mathrm{PE}$ phase of $\mathrm{Sn}_{2} \mathrm{P}_{2} \mathrm{~S}_{6}$ crystal in projection on the (010) symmetry plane.

The long range part of the dynamic matrix is formed as a sum total of rigid ion interactions between themselves and with inducted dipoles. These interactions are then determined by effective charges and polarizabilities.

An axial symmetry force field model [39] is used to describe short range interactions. Such a choice is preconditioned by the fact that this model first of all allows us to relatively easily take the fulfillment of equilibrium conditions into consideration (the absence of internal forces and strains). Secondly, the force constant has an exact physical sense, and, thirdly, it has short range interactions for the low symmetry combinations and, respectively, a great number of non-equivalent bonds, and thus can be aptly described by means of a few parameters. In this model the force constants look as follows:

$$
\Phi_{\alpha \beta}\left(l k, l^{\prime} k^{\prime}\right)=-\frac{e^{2}}{4 \pi \epsilon_{0} V_{\mathrm{c}}}\left\{\left[A\left(l k, l^{\prime} k^{\prime}-B\left(l k, l^{\prime} k^{\prime}\right)\right)\right] \frac{r_{\alpha}\left(l k, l^{\prime} k^{\prime}\right) r_{\beta}\left(l k, l^{\prime} k^{\prime}\right)}{r^{2}\left(l k, l^{\prime} k^{\prime}\right)}+\delta_{\alpha \beta} B\left(l k, l^{\prime} k^{\prime}\right)\right\},
$$

where $A\left(l k, l^{\prime} k^{\prime}\right)$ and $B\left(l k, l^{\prime} k^{\prime}\right)$ are the radial and tangential force constants, correspondingly, and

$$
\frac{\mathrm{d}^{2} \phi\left(l k, l^{\prime} k^{\prime}\right)}{\mathrm{d} r^{2}}=\frac{e^{2}}{4 \pi \epsilon_{0} V_{\mathrm{c}}} A\left(l k, l^{\prime} k^{\prime}\right), \quad \frac{1}{r} \frac{\mathrm{d} \phi}{\mathrm{d} r}=\frac{e^{2}}{4 \pi \epsilon_{0} V_{\mathrm{c}}} B\left(l k, l^{\prime} k^{\prime}\right),
$$

$\phi\left(l k, l^{\prime} k^{\prime}\right)$ is the potential energy of the $k$ atom from the $l$ elementary cell interaction with $k^{\prime}$ atom from the $l^{\prime}$ elementary cell, $r\left(l k, l^{\prime} k^{\prime}\right)$ is the interatomic distance, $V_{\mathrm{c}}$ is the elementary cell volume.

For $\mathrm{Sn}_{2} \mathrm{P}_{2} \mathrm{~S}(\mathrm{Se})_{6}$ compounds the following short range interactions have been taken into account: the internal anion interactions (between the first neighbours "phosphorus-phosphorus", "phosphorus-chalcogen", "chalcogen-chalcogen" and between the second neighbours "phosphoruschalcogen") and the external interactions (between the first neighbours "tin-chalcogen", "tinphosphorus", "chalcogen-chalcogen"). To decrease the number of parameters the force constants for the covalent "phosphorus-phosphorus", "phosphorus-chalcogen" bonds have been put down in the form $A=A^{0}\left(r^{0} / r\right)^{6}$, and for the ion-covalent "tin-chalcogen", "tin-phosphorus", "chalcogenchalcogen" bonds - in the form $A=A^{0}\left(r^{0} / r\right)^{11}$, according to the empirical rule of Morse [41].

For the final model construction it is necessary to impose static equilibrium conditions on its parameters (force constants). Satisfying such conditions will ensure the force $\left(^{*}\right)$ acting on each atom in the unit cell to be equal to zero as well as the absence of internal strains $\left(^{* *}\right)$. These additional equations also influence the decrease in the number of the model independent parameters. In case of the PE phase of crystals $\left(P 2_{1} / c\right.$ space group) there are 16 conditions $\left(12\left(^{*}\right)+4(* *)\right)$, while in case of the FE phase ( $P c$ space group) there are 31 conditions $\left(27\left(^{*}\right)+4\left(*^{*}\right)\right)$. All radial force constants from (2) have been chosen to satisfy these conditions.

As a result there has been obtained the model containing 12 independent parameters: 7 for short range interaction description, 5 for the long range interaction description (two effective charges and three polarizabilities). 


\section{Results and discussion}

The final set of parameters given in table 1, was chosen by selecting the best agreement of the calculated phonon frequencies in the Brillouin zone (BZ) centre with the frequencies obtained from the RS spectra [7,12]. To make a comparison possible table 2 gives experimental data and the values of the calculated frequencies. The values of ultrasound speed [11] were used in order to determine the model parameters.

Table 1. Polarizable ion model parameters of $\mathrm{Sn}_{2} \mathrm{P}_{2} \mathrm{~S}_{6}$ and $\mathrm{Sn}_{2} \mathrm{P}_{2} \mathrm{Se}_{6}$ crystals in the $\mathrm{FE}$ and $\mathrm{PE}$ phases (short range parameters are dimensionless quantity, effective charges in elementary charge units, polarizabilities in $\AA^{3}$ units).

\begin{tabular}{|c|c|c|c|}
\hline Force constant & $\mathrm{Sn}_{2} \mathrm{P}_{2} \mathrm{~S}_{6} \mathrm{FE}$ & $\mathrm{Sn}_{2} \mathrm{P}_{2} \mathrm{~S}_{6} \mathrm{PE}$ & $\mathrm{Sn}_{2} \mathrm{P}_{2} \mathrm{Se}_{6} \mathrm{PE}$ \\
\hline$A_{\mathrm{P}-\mathrm{P}}^{0}$ & 215 & 216 & 177 \\
$A_{\mathrm{P}-\mathrm{X}}^{0}$ (near. neigb.) & 283 & 248 & 227 \\
$A_{\mathrm{P}-\mathrm{X}}^{0}$ (next near. neigb.) & -6 & 1 & 4 \\
$A_{\mathrm{Sn}-\mathrm{X}}^{0}$ & 27 & 15 & 27 \\
$A_{\mathrm{Sn}-\mathrm{P}}^{0}$ & -2 & -3 & -9 \\
$A_{\mathrm{X}-\mathrm{X}}^{0}$ (inter anion) & 11 & 14 & 3 \\
$A_{\mathrm{X}-\mathrm{X}}^{0}$ (intra anion) & 21 & 19 & 25 \\
$Z_{\mathrm{Sn}}$ & 1.2 & 1.45 & 0.91 \\
$Z_{\mathrm{X}}$ & 0.42 & 0.33 & 0.49 \\
$Z_{\mathrm{P}}$ & 0.54 & 0.59 & 0.47 \\
$\alpha_{\mathrm{Sn}}$ & 1.5 & 3.3 & 4.5 \\
$\alpha_{\mathrm{X}}$ & 2.8 & 1.1 & 1.7 \\
$\alpha_{\mathrm{P}}$ & 0.6 & 1.3 & 0.05 \\
\hline
\end{tabular}

Phonon spectra. The group-theoretical analysis of $\mathrm{Sn}_{2} \mathrm{P}_{2} \mathrm{~S}_{6}$ and $\mathrm{Sn}_{2} \mathrm{P}_{2} \mathrm{Se}_{6}$ crystals shows that in the PE phase in the BZ centre there takes place the following symmetry distribution: $\Gamma_{\text {opt. }}=$ $15 A_{g}+15 B_{g}+14 A_{u}+13 B_{u}$ and in the FE phase - as $\Gamma_{\text {opt. }}=28 A^{\prime}+29 A^{\prime \prime}$. The acoustic vibrations are accordingly subdivided into $\Gamma_{\text {acous. }}=A_{u}+2 B_{u}$ and $\Gamma_{\text {acous. }}=2 A^{\prime}+A^{\prime \prime}$.
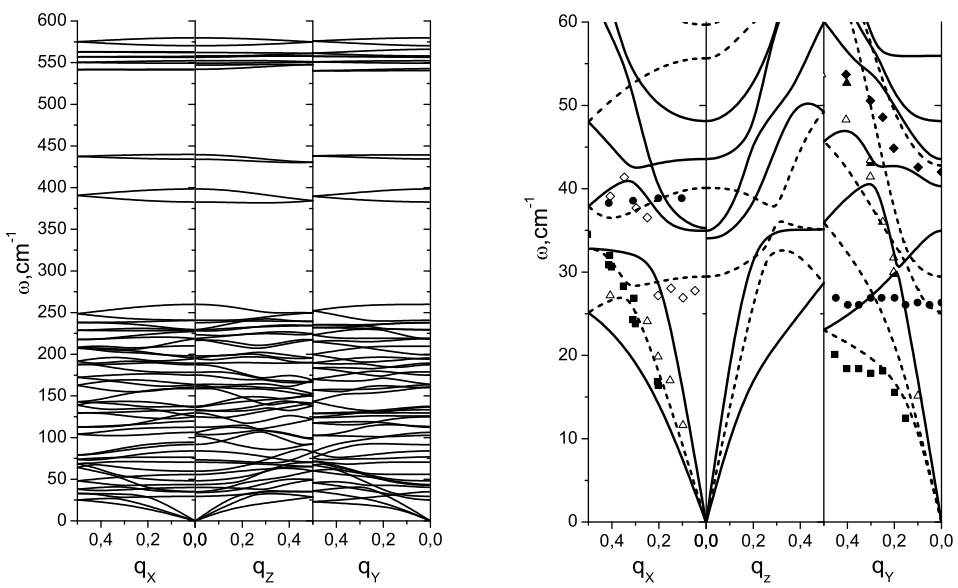

Figure 2. The calculated phonon spectrum in the PE phase of the $\mathrm{Sn}_{2} \mathrm{P}_{2} \mathrm{~S}_{6}$ crystal (left) and its low frequency part (right); points are the experimental data on neutrons' scattering [9]; the division in respect to symmetry for the low frequency part: continuous lines - symmetric $A^{\prime}$ modes for $q_{\mathrm{X}}$ and $q_{Z}$, and $A$ for $q_{Y}$, dotted lines - asymmetric $A^{\prime \prime}$ modes for $q_{\mathrm{X}}$ and $q_{Z}$, and $B$ for $q_{Y}$.

The calculated $\mathrm{Sn}_{2} \mathrm{P}_{2} \mathrm{~S}_{6}$ crystal phonon spectrum in the PE phase and its low frequency part is represented in figure 2, and in the FE phase - in figure 3. The points in these figures correspond 
Table 2. The comparison of the calculated frequencies in the BZ centre of $\mathrm{Sn}_{2} \mathrm{P}_{2} \mathrm{~S}_{6}$ and $\mathrm{Sn}_{2} \mathrm{P}_{2} \mathrm{Se}_{6}$ crystals in the FE and PE phases with the experimental data of RS spectroscopy $[7,12,42]$ $\left(\left(A_{g}, B_{g}\right)\right.$-pairs for PE phase, $\left(A^{\prime}, A^{\prime \prime}\right)$-pairs for FE phase).

\begin{tabular}{|c|c|c|c|c|c|}
\hline \multicolumn{2}{|c|}{$\mathrm{Sn}_{2} \mathrm{P}_{2} \mathrm{~S}_{6} \quad F E$} & \multicolumn{2}{|c|}{$\mathrm{Sn}_{2} \mathrm{P}_{2} \mathrm{~S}_{6} \quad P E$} & \multicolumn{2}{|c|}{$\mathrm{Sn}_{2} \mathrm{P}_{2} \mathrm{Se}_{6} \quad P E$} \\
\hline$\omega_{\text {exp }}, \mathrm{cm}^{-1}$ & $\omega_{\text {theor }}, \mathrm{cm}^{-1}$ & $\omega_{\text {exp }}, \mathrm{cm}^{-1}$ & $\omega_{\text {theor }}, \mathrm{cm}^{-1}$ & $\omega_{\exp }, \mathrm{cm}^{-1}$ & $\omega_{\text {theor }}, \mathrm{cm}^{-1}$ \\
\hline 29 & 29 & 26 & 35 & 16 & 28 \\
\hline 40 & 36 & 26 & 29 & 16 & 35 \\
\hline 33 & 33 & 35 & 43 & 35 & 36 \\
\hline 53 & 42 & 41 & 70 & - & 41 \\
\hline 54 & 58 & 52 & 48 & 52 & 39 \\
\hline 59 & 61 & 68 & 83 & 52 & 51 \\
\hline 109 & 96 & 87 & 106 & - & 48 \\
\hline 120 & 116 & 86 & 112 & 59 & 60 \\
\hline 120 & 131 & 115 & 125 & 62 & 54 \\
\hline 132 & 137 & - & 129 & - & 77 \\
\hline- & 140 & 144 & 137 & 85 & 80 \\
\hline 154 & 155 & 142 & 133 & 88 & 84 \\
\hline 179 & 171 & 169 & 160 & - & 84 \\
\hline 185 & 170 & 187 & 163 & - & 99 \\
\hline- & 201 & 190 & 187 & - & 96 \\
\hline 194 & 193 & 194 & 189 & - & 106 \\
\hline 204 & 213 & 205 & 195 & 114 & 132 \\
\hline 215 & 204 & 215 & 219 & 114 & 113 \\
\hline 245 & 237 & 249 & 229 & 147 & 142 \\
\hline 248 & 225 & 247 & 229 & 148 & 140 \\
\hline 263 & 279 & 260 & 240 & 152 & 152 \\
\hline 279 & 296 & 278 & 259 & 162 & 154 \\
\hline 381 & 397 & 381 & 398 & 217 & 231 \\
\hline 382 & 386 & 381 & 382 & 217 & 232 \\
\hline 556 & 554 & 555 & 552 & 444 & 440 \\
\hline 556 & 556 & 556 & 550 & 444 & 440 \\
\hline 569 & 567 & 567 & 556 & 454 & 456 \\
\hline 572 & 565 & 561 & 557 & 454 & 458 \\
\hline 597 & 589 & - & 570 & 482 & 482 \\
\hline 598 & 599 & 580 & 580 & 482 & 482 \\
\hline
\end{tabular}
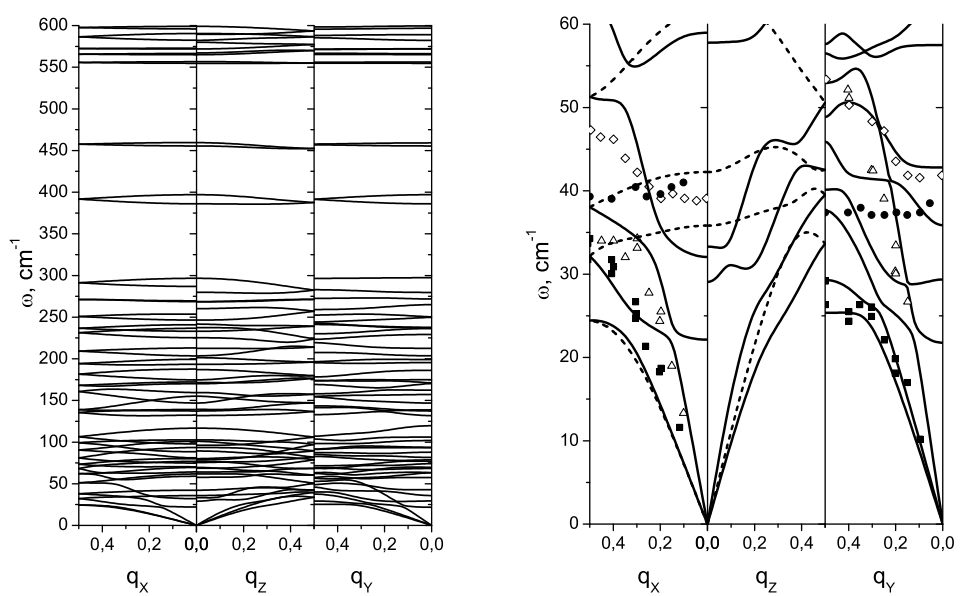

Figure 3. The calculated phonon spectrum in the $\mathrm{FE}$ phase of the $\mathrm{Sn}_{2} \mathrm{P}_{2} \mathrm{~S}_{6}$ crystal (left) and its low frequency part (right); points are the experimental data on neutrons' scattering [9]; the division in respect to symmetry for the low frequency part: continuous lines - symmetric $A^{\prime}$ modes for $q_{\mathrm{X}}$ and $q_{Z}$, dotted lines - asymmetric $A^{\prime \prime}$ modes for $q_{\mathrm{X}}$ and $q_{Z}$; in the direction of $q_{Y}$ all the modes reach the general $A$ symmetry. 
to the neutron scattering data [9]. It should be noted that all these data have not been taken into consideration while choosing the model parameters. Therefore, a rather satisfactory coincidence of the calculated low energy phonon branches with the experiment carried out may be interpreted as a proof of the model correspondence to the real situation. As it is seen in figures, the division into external and internal vibrations of the crystal lattice may be drawn only relatively as far as the frequency limit of lattice external vibrations (near $140 \mathrm{~cm}^{-1}$ for both phases) approximately borders on the frequency region of internal deformation vibrations of the anion complexes (from 140 to $260 \mathrm{~cm}^{-1}$ ). The valent vibrations of $\mathrm{P}-\mathrm{P}$ and $\mathrm{P}-\mathrm{S}$ bonds located in the region from 380 to $600 \mathrm{~cm}^{-1}$ are more highly energetic. The eigenvector analysis of the given vibrations has shown that they are mixed ones. However, the vibrations with the frequency at about $380 \mathrm{~cm}^{-1}$ are predominantly valent to the $\mathrm{P}-\mathrm{P}$ bonds vibrations in contrast to the data given in [20] where it is assumed that this internal mode is a mainly valent $\mathrm{P}-\mathrm{S}$ bond vibrations. Here it is quite to the point to remind that the experimental data on the concentration transformation of RS spectra in $\mathrm{Sn}_{2} \mathrm{P}_{2}\left(\mathrm{Se}_{x} \mathrm{~S}_{1-x}\right)_{6}$ solid solutions testify to the possible interpretation of this mode as an vibration with a predominant contribution to the $\mathrm{P}-\mathrm{P}$ bonds length change.
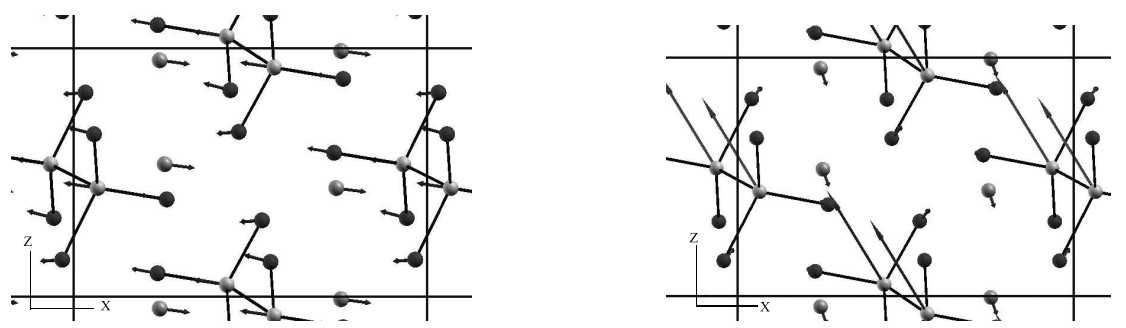

Figure 4. The projection on the (010) symmetry plane of eigenvector of low energy $B_{u}$ vibration of the crystal lattice in PE phase of $\mathrm{Sn}_{2} \mathrm{P}_{2} \mathrm{~S}_{6}$ crystals (left) and $\mathrm{Sn}_{2} \mathrm{P}_{2} \mathrm{Se}_{6}$ crystals (right).

Here let us dwell in greater detail upon the $\mathrm{Sn}_{2} \mathrm{P}_{2} \mathrm{~S}_{6}$ crystal lattice dynamics in the PE phase. Consider $q_{Z}$ direction in the BZ. Under the ferroelectric PT in these crystals $\left(P 2_{1} / c \rightarrow P c\right)$ there occurs a condensation of the transversal optical mode of $B_{u}$ symmetry in the BZ centre. The lowest calculated $B_{u}$ symmetry optical mode is transversal and polarized in the symmetry plane close to [100] direction (see figure 4). Its eigenvector may be considered to correspond to the PT order
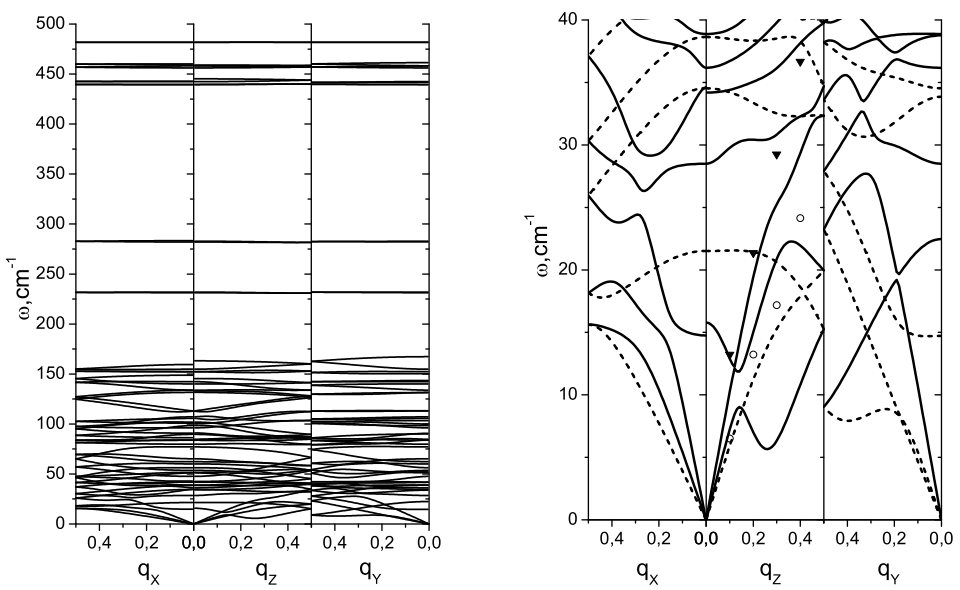

Figure 5. The calculated phonon spectrum in the PE phase of the $\mathrm{Sn}_{2} \mathrm{P}_{2} \mathrm{Se}_{6}$ crystal (left) and its low frequency part (right); points are the experimental data on neutrons' scattering [10]; the division in respect to symmetry for the low frequency part: continuous lines - symmetry $A^{\prime}$ modes for $q_{\mathrm{X}}$ and $q_{Z}$, and $A$ for $q_{Y}$, dotted lines - symmetry $A^{\prime \prime}$ modes for $q_{\mathrm{X}}$ and $q_{Z}$, and $B$ for $q_{Y}$. 
parameter. The dispersion branch of the given mode has its minimum in the BZ centre, as distinct from the case of the $\mathrm{Sn}_{2} \mathrm{P}_{2} \mathrm{Se}_{6}$ crystal (see below). Though the interaction of this optical vibration with the acoustic ones is possible no peculiarities in the form of the dispersion branches of the latter have been observed. Certainly, in the real situation the interaction between vibrations, allowed by their symmetry, leads to the condensing of mixed phonons under the PT. The contribution of each mode into the unstable oscillation may be evaluated by trying to decompose the atom displacement vector transforming the crystal structure from one phase into another, according to eigenvector of the highly symmetrical phase modes. Such an estimation for $\mathrm{Sn}_{2} \mathrm{P}_{2} \mathrm{~S}_{6}$ crystal has shown that the major contribution into such displacement vector is made by four modes: the lowest $B_{u}\left(34 \mathrm{~cm}^{-1}\right)$ mode and the 3 lowest $A_{g}\left(35,43,48 \mathrm{~cm}^{-1}\right)$ modes in the proportion of $40: 7: 9: 9$, respectively. That is, in other words, the dynamic instability under the PT in this crystal is to a certain degree determined by the interaction, obviously a non-linear one, of the optic $B_{u}$ polar vibration with the fully symmetrical $A_{g}$ modes. Beyond any doubt, a certain role is played here by the linear interaction of the mode with the same symmetry. The data on the RS spectra temperature dependence in the $\mathrm{Sn}_{2} \mathrm{P}_{2} \mathrm{~S}_{6}$ crystal testify to this fact [7]. It should be noted that such a procedure was performed for the case of the model parameter set, which correspond to the modelled instability (see page 689), and the same result was obtained.

The calculated phonon spectrum of the $\mathrm{Sn}_{2} \mathrm{P}_{2} \mathrm{Se}_{6}$ crystal in the PE phase and its low frequency part are represented in figure 5. In general, the vibrational spectrum of selenium compound is similar to that of the sulfur compound. The difference lies in the fact that the borderline between the lattice external and internal vibrations of the $\mathrm{Sn}_{2} \mathrm{P}_{2} \mathrm{Se}_{6}$ crystals is located near $80 \mathrm{~cm}^{-1}$, the deformation vibrations of the $\mathrm{P}_{2} \mathrm{Se}_{6}$ anions are in the region from 80 to $160 \mathrm{~cm}^{-1}$, and the valent ones - from 230 to $480 \mathrm{~cm}^{-1}$.

The peculiar feature of the spectrum is a clearly defined minimum of the low energy optical branch (with $B_{u}$ symmetry in the BZ centre) under $q_{Z} \approx 0.15$. The linear interaction of the given mode with the transversal acoustic vibrations having the same symmetry $\left(A^{\prime}\right)$ and polarized in the symmetry plane, preconditions the presence of a clearly defined minimum in the acoustic branch under $q_{Z} \approx 0.25$. The given situation coincides in a qualitative respect with the experimentally observed pictures [2] - in $\mathrm{Sn}_{2} \mathrm{P}_{2} \mathrm{Se}_{6}$ crystals at cooling there takes place the realization of the sequence in the PTs of the second and the first order. The transition from high temperature nonpolar phase into the polar phase is reached through the modulated incommensurate phase. The modulation period of this phase increases while cooling and makes up $12-14$ unit cell, which corresponds to the condensation of phonons at approximately $q \approx 0.1$ and the modulation vector is directed close to $q_{Z}$ direction in the symmetry plane [23].

Thus, in $\mathrm{Sn}_{2} \mathrm{P}_{2} \mathrm{Se}_{6}$ and $\mathrm{Sn}_{2} \mathrm{P}_{2} \mathrm{~S}_{6}$ crystals in the calculations of the lattice dynamics in the polarizable ion model there has been discovered an essentially different form of dispersion branches of the transversal optical vibrations, connected with the PT and acoustic branches interacting with them.
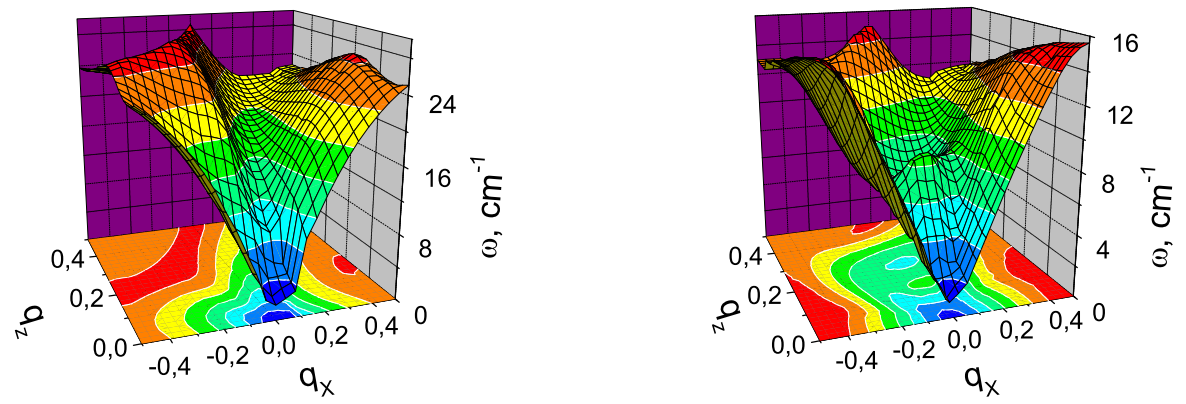

Figure 6. The energy surface, calculated in the symmetry plane, of the lowest acoustic vibration in PE phase of $\mathrm{Sn}_{2} \mathrm{P}_{2} \mathrm{~S}_{6}$ crystals (left) and $\mathrm{Sn}_{2} \mathrm{P}_{2} \mathrm{Se}_{6}$ crystals (right). 
Calculations of the orientation dependence of the phonon spectra have been made to check the absence of the BZ minima in other directions in the phonon dispersion curves. Such counts have proved their absence. In figure 6, for example, there is given a dispersion surface form of the low energy acoustic vibrations in the (010) reciprocal plane. As it is seen, there is a clearly marked difference: for the $\mathrm{Sn}_{2} \mathrm{P}_{2} \mathrm{Se}_{6}$ crystal there can be observed a minimum in the direction close to $q_{Z}$ (in accordance with the experiment in [23], the deviation is at about $9^{\circ}$, in the calculations $-3^{\circ}$ ), for the $\mathrm{Sn}_{2} \mathrm{P}_{2} \mathrm{~S}_{6}$ a minimum is absent.

The calculations given for the acoustic surfaces enable one to make a comparison of the sound velocity orientation dependencies obtained theoretically with those received experimentally on BS [43] (figure 7). As it is seen, the polarizable ion model qualitatively reflects anisotropy of $\mathrm{Sn}_{2} \mathrm{P}_{2} \mathrm{~S}_{6}$ crystal elastic properties. As long as the BS spectroscopy data are not available for $\mathrm{Sn}_{2} \mathrm{P}_{2} \mathrm{Se}_{6}$ crystals, then to make a comparison possible there has been given the sound velocity dependence, experimentally investigated for the $\mathrm{Sn}_{2} \mathrm{P}_{2}\left(\mathrm{Se}_{0.28} \mathrm{~S}_{0.72}\right)_{6}$ solid solution. This chemical composition corresponds to the LP concentration in the phase diagram - under $x>0.28$ there arises an incommensurate phase. The condensation of the mixed optical and acoustic phonons under $q_{Z}>0$, described above for the $\mathrm{Sn}_{2} \mathrm{P}_{2} \mathrm{Se}_{6}$ crystal, is closely connected [10] with the incommensurate phase.

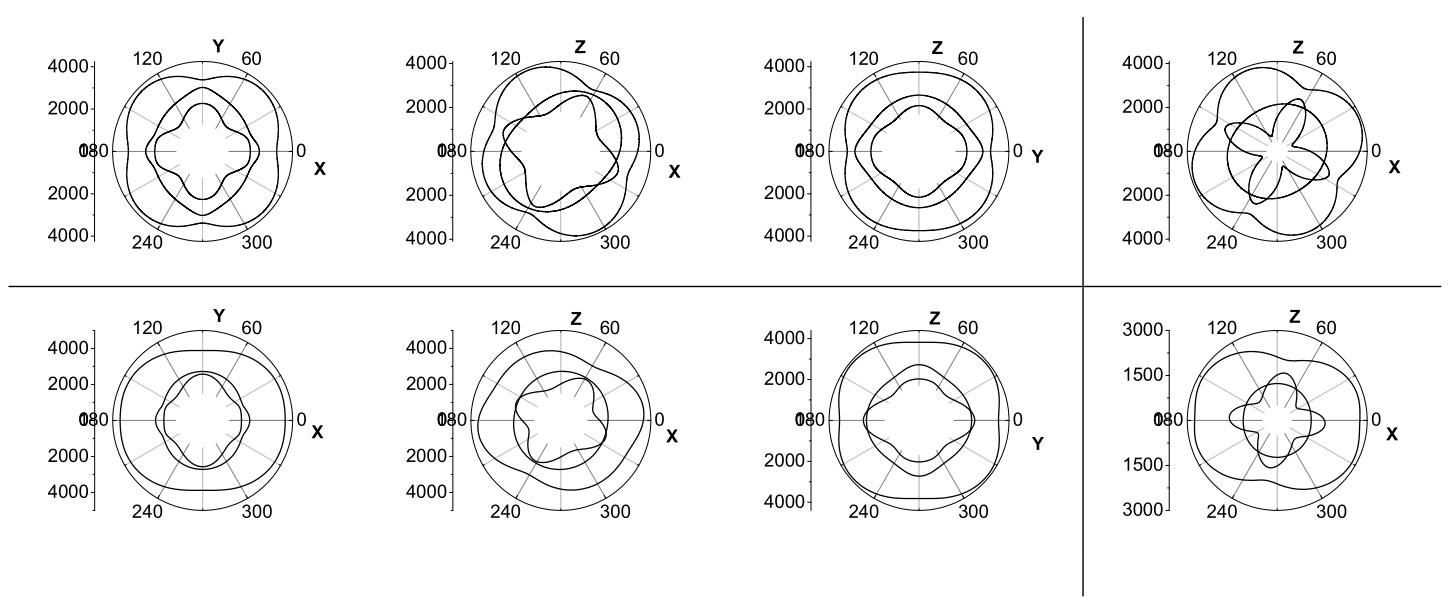

Figure 7. The experimentally obtained [43] (top) and the calculated indicatrix (bottom) of the sound velocities in $\mathrm{PE}$ phase of $\mathrm{Sn}_{2} \mathrm{P}_{2} \mathrm{~S}_{6}$ crystals (left) and $\mathrm{Sn}_{2} \mathrm{P}_{2} \mathrm{Se}_{6}$ crystals (right). The experimental data for the $\mathrm{Sn}_{2} \mathrm{P}_{2} \mathrm{Se}_{6}$ crystal have been substituted by the similar ones for the $\mathrm{Sn}_{2} \mathrm{P}_{2}\left(\mathrm{Se}_{0.28} \mathrm{~S}_{0.72}\right)_{6}$ solid solution.

The lattice instability. To understand the cause of the lattice instability emergence and to state its differences in $\mathrm{Sn}_{2} \mathrm{P}_{2} \mathrm{~S}_{6}$ and $\mathrm{Sn}_{2} \mathrm{P}_{2} \mathrm{Se}_{6}$ compounds there has been made a modelling to display the possibilities of the optical phonon condensation. To begin with, it has been decided to try and get the lattice instability by modelling temperature change by means of taking into account temperature expansion. With this aim in view there have been used the experimental values of linear temperature expansion coefficient [23]. At the corresponding change of the unit cell volume the modelling of dynamic instability has not been achieved. The volume decrease has led to a monotonous increase of the optical phonon frequencies. Evidently, the change in the unit cell sizes is by far not the major factor that initiates the appearance of the structural changes. This is not surprising, since at the pressure increase the PT temperature is lowered in a given crystal, i.e. there takes place the PE phase stabilization [44]. Thus, the two factors defining the unit cell volume decrease, cooling and mechanical pressure, influence the centrosymmetrical phase stabilization in the opposite way.

Therefore, the most acceptable seems to be the attempt of obtaining the dynamic instability in the model used by varying its parameters. As far as the displacement of the cation sublattice in relation to the anion sublattice plays the major role in the $\mathrm{PT}$, the modelling has been made by changing the parameters responsible for the interactions of sublattices. There has been made use 
of the change in the radial force constant $A_{\mathrm{Sn}-\mathrm{S} / \mathrm{Se}}$, effective charges and ion polarizabilities. The static equilibrium conditions were satisfied again at a new set of the model parameters.
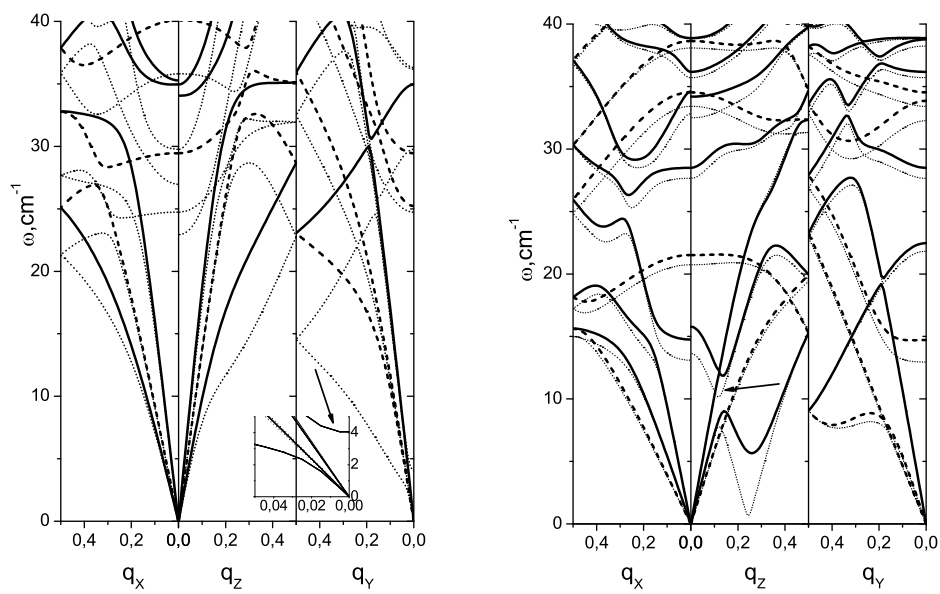

Figure 8. Different types of the modelled lattice instability in PE phase of $\mathrm{Sn}_{2} \mathrm{P}_{2} \mathrm{~S}_{6}$ crystals (left) and $\mathrm{Sn}_{2} \mathrm{P}_{2} \mathrm{Se}_{6}$ crystals (right) (doted lines as compared with solid and dashed ones (see figure 2), the arrow points at the soft optic mode location).

In case of $\mathrm{Sn}_{2} \mathrm{P}_{2} \mathrm{~S}_{6}$ the change of the model parameters leads to the condensation of optical phonons in the BZ centre. The instability on figure 8, for example, was obtained at about $3 \%$ increase of the tin ions effective charges with corresponding change of the sulfur ions effective charges. It should be noted that the optical mode softening takes place in the $q_{Y}$ direction. This can be explained by the fact that symmetry $B_{u}$ phonons propagating in the plane of $X O Z$ symmetry are skew (quasitransversal or quasilongitudinal) ones. This adds them a rigidity at the expense of the macrofield in comparison with the transversal $B_{u}$ phonons propagating in the $q_{Y}$ direction.

The analysis of the data obtained enables one to affirm that the most tangible contribution into the emergence of the lattice instability is made by the recharging between the atoms of tin and chalcogen. Then the following situation may be observed: the change of ion charges in its turn calls for the change of their polarizabilities. There is a disbalance of forces and the system becomes unstable in relation to a certain vibration. To stabilize the frequency of the symmetry $A^{\prime}$ soft optic mode in the $\mathrm{FE}$ phase of $\mathrm{Sn}_{2} \mathrm{P}_{2} \mathrm{~S}_{6}$ the displacement of tin atoms from their centrosymmetrical positions and a reverse recharging process is necessary. Certainly, in the FE phase there will be other model parameters (see table 1).

In case of $\mathrm{Sn}_{2} \mathrm{P}_{2} \mathrm{Se}_{6}$ the change of the model parameters leads to condensation of the mixed optic and acoustic phonons under $q_{Z} \approx 0.25$. And namely at decreasing $A_{\mathrm{Sn}-\mathrm{Se}}$ constant, at increasing ion palarizability and a recharging between the tin and selenium atoms there takes place the given condensation of the interacting optical and acoustic phonons with small changes of other phonon branches (figure 8, dotted lines).

It is interesting to understand the reason for different character of phase transitions for $\mathrm{Sn}_{2} \mathrm{P}_{2} \mathrm{~S}_{6}$ and $\mathrm{Sn}_{2} \mathrm{P}_{2} \mathrm{Se}_{6}$ crystals possessing a similar structure. With this aim in view there has been conducted the investigation concerning the influence of different interactions on the form of the dispersion branches of the low energy optic phonons.

While taking into account a short range and Coulomb interaction only (the rigid ion model, figure 9) the form of the dispersion branches changes up to monotonously growing curves with a minimum frequency value in the BZ centre. The instability modelling in this case shows that the phonon condensation takes place under $q_{Y} \rightarrow 0$ for both compounds. It is likely that at the expense of the macrofield the vibrations with the $q_{Z}$ direction of propagating have an additional hardness. The evident $L O-T O$ splitting increases with the condensation of phonons and more essentially in the $\mathrm{Sn}_{2} \mathrm{P}_{2} \mathrm{~S}_{6}$ crystal with higher values of effective charges. 

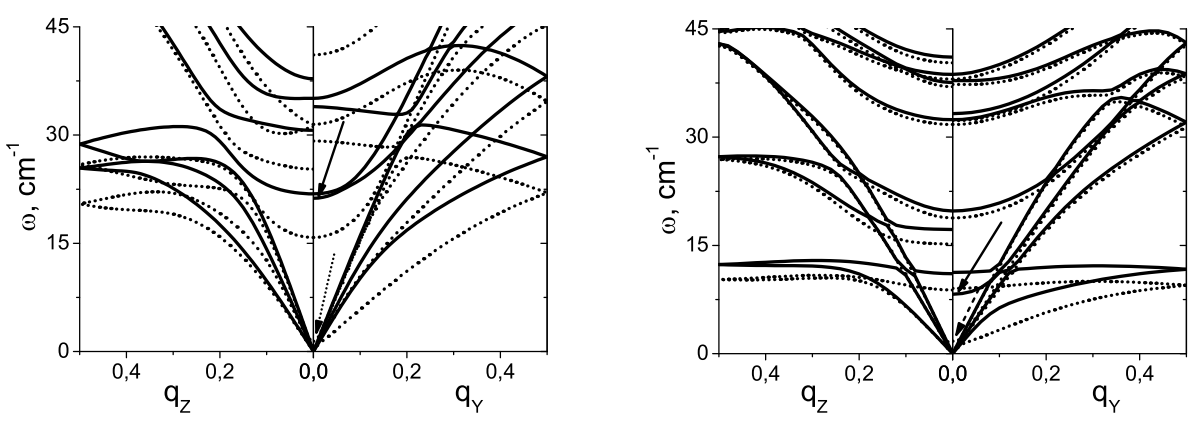

Figure 9. The calculated phonon spectra in the PE phase of the $\mathrm{Sn}_{2} \mathrm{P}_{2} \mathrm{~S}_{6}$ (left) and $\mathrm{Sn}_{2} \mathrm{P}_{2} \mathrm{Se}_{6}$ (right) crystals in the rigid ion model. The solid lines correspond to the model parameters with the stable phonon spectra, the dotted ones correspond to the modelled dynamic instability; the arrows point to the initial (stable) and final (unstable) location of the optic mode under destabilization.

Taking the polarizability of ions into consideration cardinally changes the situation (figure 8). The frequency of the lowest optic $B_{u}$ mode (under $q=0$ ) is decreasing, but the form of its dispersion branch is characterized by its minimum near $q_{Z} \approx 0.25$ for selenium and at $q=0$ for sulfur compounds. The modelling of instability reconstructs the experimentally observable pictures of the phonon mode instability. Thus the very consideration of ions polarizability is an important factor in constructing the adequate model of lattice dynamics and its instability in $\mathrm{Sn}_{2} \mathrm{P}_{2} \mathrm{~S}(\mathrm{Se})_{6}$ crystals. This explains the impossibility of getting a correct symmetrical description of the soft optic mode and the respective form of its dispersion branches within the framework of the rigid ion model [19].

Thus, the change in polarizability of ions and their charge state essentially influence the dispersion type of the soft optic mode of the crystals under investigation. Evidently, there should be a clear difference in the form of these normal oscillations eigenvectors. The analysis of the eigenvectors of the $\mathrm{Sn}_{2} \mathrm{P}_{2} \mathrm{~S}_{6}$ crystal low energy optic modes has shown that they almost do not possess the contribution from $\mathrm{P}_{2} \mathrm{~S}_{6}$ complexes translations. Only the soft optic mode (see figure 4) has proved to be an exception, in which besides cation movement, there is a contribution of anion translation and their slight deformation. It means that a soft optic vibration creates a dipole having three constituents: a displacement of the cation sublattice relatively to the anion sublattice, a relative displacement of two anions in the unit cell and deformation of anions. Contrary to this, while considering the form of eigenvectors in the $\mathrm{Sn}_{2} \mathrm{P}_{2} \mathrm{Se}_{6}$ crystal lower optic modes it has turned out that all of them contain a contribution from the anion movement. The contribution of cation translations into the soft optic mode is slight while the contribution from anion deformations is dominating (see figure 4).

Solid solutions. The experimental data on the RS spectroscopy for solid solutions based on the $\mathrm{Sn}_{2} \mathrm{P}_{2} \mathrm{~S}_{6}$ and $\mathrm{Sn}_{2} \mathrm{P}_{2} \mathrm{Se}_{6}$ compounds testify to a predominantly one-mode behavior of the crystal lattice external vibrations and the soft optic phonon, in particular [45]. However, the question still remains not cleared up as to which real changes occur in the dispersion branch while sulfur atom is being displaced by selenium atom. To make it clear we have made the calculations concerning the lattice dynamics of $\mathrm{Sn}_{2} \mathrm{P}_{2}\left(\mathrm{Se}_{x} \mathrm{~S}_{1-x}\right)_{6}$ solid solutions within the framework of the average crystal model. This model employs a linear approximation for the concentration dependence of all parameters defining the phonon spectrum. Of course, such a model is very simplified. However, the similarity in the structure of the compounds of the end members, the static character of chalcogen atom substitution in mixed crystals [45] enable one to expect the corresponding description of the concentration transformation of the phonon spectrum lower energy part.

The results of the calculations are as follows (figure 10). For crystals with $0<x<0.33$ selenium concentration there takes place a condensation of phonons in the BZ centre similar to the one in 

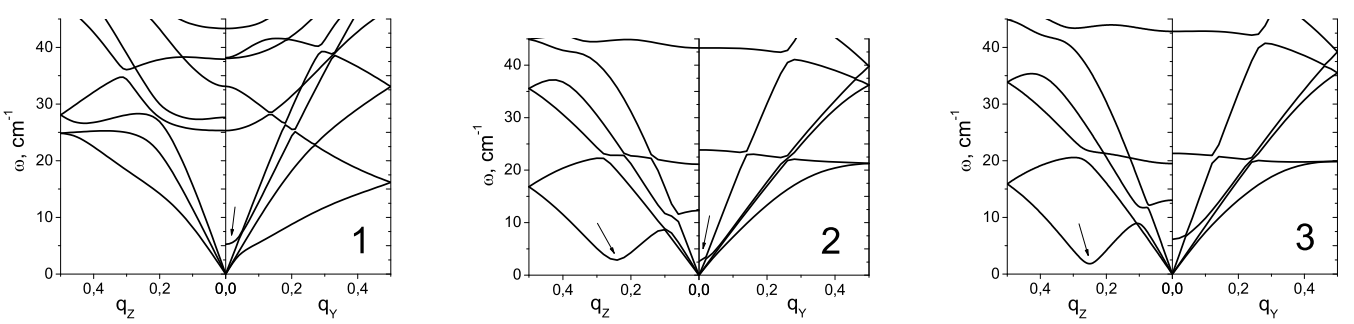

Figure 10. Different types of lattice instability modelled in $\operatorname{Sn}_{2} \mathrm{P}_{2}\left(\mathrm{Se}_{x} \mathrm{~S}_{1-x}\right)_{6}$ solid solution: $x=0.25$ $-1, x=0.33-2, x=0.4-3$; the arrows point to the phonon branches being condensed.

the case of $\mathrm{Sn}_{2} \mathrm{P}_{2} \mathrm{~S}_{6}$ crystals. At the $0.33<x<1$ values, condensation occurs under $q_{Z} \approx 0.25$, as in the case of $\mathrm{Sn}_{2} \mathrm{P}_{2} \mathrm{Se}_{6}$ crystals. For the composition near $x \approx 0.33$, there is being simultaneously modelled the condensation of phonons in the BZ centre as well as outside it (see figure 10). It means that in our model there has been obtained a "two-mode" concentration transformation for the fluctuation order parameter spectrum. The reason for this situation is a strong linear interaction between soft optic branch and transverse acoustic phonons propagating along $q_{Z}$ direction. Here the values of $L O-T O$ splitting of soft optic phonons, which are polarized and propagate in monoclinic symmetry plane, depend on selenium concentration. It should be noted that the independence on the concentration of the wave vector of modulation $\left(q_{Z} \approx 0.25\right)$ has no agreement with $\mathrm{X}$-ray diffraction data given in the work [23], where they have obtained the expected case behavior $q^{2} \sim\left(x-x_{L P}\right)$ for the LP on the second order PT line $T_{i}(x)$ which separates PE and IC phases in the region $0.28 \leqslant x \leqslant 1$. At the same time it should be noted that experimental data for only three values of selenium concentration $x=0.6,0.8,1.0$ are available, and additional investigations are necessary to clearly define the concentration behavior of the modulation of the incommensurate phase in the vicinity of LP. It is desirable to carry out further investigations of phonon spectra evolution in $\mathrm{Sn}_{2} \mathrm{P}_{2}\left(\mathrm{Se}_{x} \mathrm{~S}_{1-x}\right)_{6}$ solid solution under transition through the LP in lattice dynamics models that allows for essential anharmonicity and strong electron-phonon interaction. Obviously, the improved polarizable ion model which has takes into account the anharmonicity of electron shell interaction with their core, will be more adequate in describing the order parameter fluctuation spectra peculiarities of PT in the vicinity of LP which includes relaxation dynamics and ion recharging.

\section{Conclusions}

To describe the lattice dynamics in $\mathrm{Sn}_{2} \mathrm{P}_{2} \mathrm{~S}(\mathrm{Se})_{6}$ crystals there has been used the model of polarizable ions. There has been obtained a good agreement of the calculated phonon spectra with the experimental data of Raman and Brillouin spectroscopies, neutron scattering and ultrasound experiments.

The soft optic mode instability of the PE phase is modelled by means of recharging between cations $\mathrm{Sn}^{2+}$ and anion $\left[\mathrm{P}_{2} \mathrm{~S}(\mathrm{Se})_{6}\right]^{4-}$. By increasing the negative charge of chalcogen atoms as well as by raising their polarizability, it lowers the soft optic mode frequency. The space dispersion of fluctuation rigidity of the PT order parameter, (polarization) is reflected in the interaction of the dispersion branch of soft optic phonons with acoustic branches. For the $\mathrm{Sn}_{2} \mathrm{P}_{2} \mathrm{~S}_{6}$ crystal the symmetry $B_{u}$ soft optic mode is condensated in the BZ centre which is connected with the second order PT from the PE phase into the FE phase, $P 2_{1} / c \rightarrow P c$. The frequency stabilization of the $A^{\prime}$ soft optic mode in the FE phase is modelled by displacing $S n$ atom from the centrosymmetrical positions and a partial reversal recharging. In the $\mathrm{Sn}_{2} \mathrm{P}_{2} \mathrm{Se}_{6}$ crystal there is a condensation of the mixed linearly interacting optical and acoustic phonons near $q_{Z} \approx 0.2$, which is connected with the PT of the second order from the PE phase into the IC phase.

The above mentioned difference in dynamic instability character in sulfur and selenium crystals is caused by higher values of effective ion charges in $\mathrm{Sn}_{2} \mathrm{P}_{2} \mathrm{~S}_{6}$ crystal in comparison with $\mathrm{Sn}_{2} \mathrm{P}_{2} \mathrm{Se}_{6}$. 
This determines a greater $L O-T O$ splitting of soft optic phonons in PE phase which are polarized and propagate in monoclinic symmetry plane. The dipole-dipole interaction reduction under sulfur by selenium substitution takes effect on increasing the interaction between soft optic branch and quasitransversal acoustic branch, and their condensation at $q_{Z}>0$ which determines the occurrence of IC phase on $T-x$ phase diagram of $\mathrm{Sn}_{2} \mathrm{P}_{2}\left(\mathrm{Se}_{x} \mathrm{~S}_{1-x}\right)_{6}$ solid solution at $x>0.28$. In the vicinity of LP, at $x \approx 0.28$, there has been modelled a simultaneous condensation of soft optic mode in BZ centre and mixed optic and acoustic phonons at $q_{Z}>0$. Such a peculiarity of ("two-mode" behavior) phonon spectra concentration transformation of ferroelectrics-semiconductors $\mathrm{Sn}_{2} \mathrm{P}_{2} \mathrm{~S}(\mathrm{Se})_{6}$ is probably connected with experimentally observed long-term changes of dielectric and acoustic properties of $\mathrm{Sn}_{2} \mathrm{P}_{2} \mathrm{~S}_{6}$ crystal in the vicinity of $\mathrm{LP}$, and is required for further investigations.

\section{References}

1. Gomonnai A.V., Grabar A.A., Vysochanskii Yu.M. et al., Fiz. Tverd. Tela, 1981, 23, 3602 (in Russian).

2. Vysochanskii Yu.M., Slivka V.Yu., Sov. Phys. Usp., 1992, 35, 123.

3. Vysochanskii Yu.M., Maior M.M., Rizak V.M. et al., JETF, 1989, 45, No. 4, 1365.

4. Khoma M.M., Molnar A.A., Vysochanskii Yu.M., J. Phys.St., 2, No 4, 1998, 535.

5. Berezovsky S.V., Korda V.Yu., Klepikov V.F., Phys. Rev B, 2001, 64, 64103.

6. Van Raaij G.H.V., Rubtsov A.N., Janssen T., Ferroelectrics, 2000, 240, 163; Rubtsov A.N., Janssen T., Europhys. Lett., 2001, 53, 216; Van Raaij G.H.V., Janssen T., Ferroelectrics, 2001, 250, 135.

7. Bokotei A.A., Vysochanskii Yu.M., Rizak V.M., Stefanovich V.A., Gurzan M.I., Ukr. Fiz. J., 1997, 42, No. 1, 62; Vysochanskii Yu.M., Slivka V.Yu., Voroshilov Yu.V., Gurzan M.I., Chepur D.V., Fiz. Tverd. Tela, 1979, 21, 215.

8. Ritus A.I., Roslick M.S., Vysochanskii Yu.M., Grabar A.A., Slivka V.Yu., Fiz. Tverd. Tela, 1985, 27, 2225 (in Russian).

9. Eijt S.W.H., Currat R., Lorenzo J.E., Saint-Gregoire P., Hennion B., Vysochanskii Yu.M., Eur. Phys. J. B, 1998, 5, 169.

10. Eijt S.W.H., Currat R., Lorenzo E.J., Saint-Gregoire P., Katano S., Janssen T., Hennion B., Vysochanskii Yu., J. Phys.: Condens. Matter., 1998, 10, 4811.

11. Valyavichus V.D., Samulionis V.I., Vysochanskii Yu.M., Fiz. Tverd. Tela, 1989, 31, 144 (in Russian).

12. Hlinka J., Gregora I., et al., Phys. Rev B, 2002, 65, No. 6, 9.

13. Hlinka J., Janssen T., Dvorak V., J. Phys.: Condens. Matter., 1999, 11, 3209-3216.

14. Vysochanskii Yu.M., Drobnich A.V., Condens. Matter Phys., 2002, 5, No. 4(32), 683.

15. Vysochanskii Yu.M., Drobnich A.V., Ferroelectrics, 2000, 236, 105.

16. Vysochanskii Yu.M., Furtsev V.G., Rizak V.M., Slivka V.Yu., Ukr. Fiz. J., 1986, 31, 908.

17. Van Loosdrecht P.H.M., Maior M.M., Molnar Sh.B., Vysochanskii Yu.M. et al., Phys. Rev. B., 1993, 48, 6014 .

18. Grabar A.A., Vysochanskii Yu.M., Slivka V.Yu., Fiz. Tverd. Tela, 1984, 26, No. 10, 3093.

19. Rizak V.M., Grabar A.A., Vysochanskii Yu.M., Slivka V.Yu., Fiz. Tverd. Tela, 1989, 31, No. 7, 160.

20. Smirnov M.B., Hlinka J., Solov'ev A.V., Phys. Rev. B, 2000, 61, No. 22, 15059.

21. Dittmar G., Schafer H., Z. Naturforsch, 1974, 29 b, No. 5-6, 317.

22. Major M.M., Vysochanskii Yu.M., Pritz I.P., Kristallografija, 1990, 35, No. 5, 1302.

23. Barsamian T.K., Khasanov S.S., Shekhman V.Sh., Ferroelectrics, 1993, 138, 77.

24. Folk R., Moser G., Phys. Rev. B, 1993, 47, 13997; Folk R., Phase Transitions, 1999, 67, 666.

25. Molnar A.A., Vysochanskii Yu.M., Horvat A.A., Nakonechnii Yu.S., Ferroelectrics, 1997, 192, 148.

26. Samulionis V., Banys J., Vysochanskii Yu., Phys. Stat. Sol. b, 1999, 215, 1156.

27. Vysochanskii Yu.M., Mitrovcij V.V., Grabar A.A., Perechinskii S.I., Motrija S.F., Kroupa J., Ferroelectrics, 2000, 237, 200.

28. Hlinka J., Currat R., de Boissieu M., Livet F., Vysochanskii Yu., Phys. Rev. B, 2005, 71, 2105.

29. Molnar A.A., Vysochanskii Yu.M., Horvat A.A., Nakonechnii Yu.S., Ferroelectrics, 1995, 174, 49.

30. Samulionis V., Banys J., Vysochanskii Yu., Ferroelectrics, 2001, 257, 140.

31. Grabar A.A., Ferroelectrics, 1997, 192, 159.

32. Al'-Shufi K., Rizak V.M., Rizak I.M., Pritz I.P., Vysochanskii Yu.M., Slivka V.Yu., Fiz. Tverd. Tela, 1993, 35, 2127.

33. Israel R., de Gelder R., Smits J.M.M., Beurskens P.T., S.W.H. Eijt, Rasing Th., van Kempen H., Maior M.M., Motrja S.F., Z. Kristallographie, 1998, 213, 34.

34. Enjalbert R., Galy J., Vysochanskii Yu.M., Ouedraogo A., Saint-Gregoire P., Eur. Phys. J. B, 1999, 8, 177 . 
35. Kuepper K., Schneider B., Caciuc V., Neumann M., Postnikov A.V., Ruediger A., Grabar A.A., Vysochanskii Yu.M., Phys. Rev. B, 2003, 67, 5107.

36. Caracas R., Gonze X., Phys. Rev. B, 2003,66, 7.

37. Rushchanskii K., Vysochanskii Yu., PHONONS-2004. 11th Intern. Confer. Abstracts, St. Petersburg, July 25-30, 2004.

38. Born M., Huang K. Dynamical theory of crystal lattices. Oxford University Press, Oxford, 1954.

39. Bruesch P. Phonons: Theory and Experiments. I. Lattice Dynamics and Models of Interatomic Forces. Springer-Verlag, Berlin, 1982, 261.

40. Scott B., Pressprich M., Willet R.D., Cleary D.A., J. Sol. Stat. Chem., 1992, 96, No. 2, 300.

41. Sherman W.F., J. Phys. C: Solid St. Phys., 1980, 13, 4613.

42. Van Loosdrecht P.H.M., Majom M.M., van Bentum P.J.M., van Kempen H., Phys. Rev. B, 1993, 48, No. 9, 6018.

43. Yevych R.M., Perechinskii S.I., Grabar A.A., Vysochanskii Yu.M., Slivka V.Yu., Condens. Matter Phys., 2003, 6, No. 2(34), 323.

44. Slivka A.G., Gerzanich E.I. et.al., Condens. Matter. Phys., 1999, 2, No. 3(19), 420.

45. Vysochanskii Yu., Stefanovich V., Mytrovcij V., Mykajlo O., Yevych R., Gurzan M., Ferroelectrics, 2002, 267, 402.

\title{
Динаміка ґратки та фазові переходи в сеґнетоелектричних кристалах $\mathrm{Sn}_{2} \mathrm{P}_{2} \mathrm{~S}(\mathrm{Se})_{6}$
}

\section{Р.М.Євич, Ю.М.Височанський}

Інститут фізики і хімії твердого тіла, Ужгородський національний університет, вул. Підгірна, 46, Ужгород, 88000, Україна

Отримано 3 серпня 2005 р., в остаточному вигляді - 31 жовтня 2005 р.

\begin{abstract}
Модель поляризованих іонів застосована для опису динаміки ґратки сеґнетоелектричних кристалів $\mathrm{Sn}_{2} \mathrm{P}_{2} \mathrm{~S}_{6}$ та $\mathrm{Sn}_{2} \mathrm{P}_{2} \mathrm{Se}_{6}$, а також їх твердих розчинів. Отримано добре узгодження розрахованих фононних спектрів з даними спектроскопії комбінаційного та мандельштам-бріллюенівського розсіювання, ультразвукових досліджень, розсіювання нейтронів. Нестабільність параелектричної фази моделюється перенесенням негативного заряду з катіонів олова на атоми халькогенів, та збільшенням поляризованості останніх. Сеґнетоелектрична фаза стабілізується зсувом атомів олова з центросиметричних позицій та частковою зворотною перезарядкою між іонами халькогену та олова. Зменшення іонних зарядів при переході від $\mathrm{Sn}_{2} \mathrm{P}_{2} \mathrm{~S}_{6}$ до $\mathrm{Sn}_{2} \mathrm{P}_{2} \mathrm{Se}_{6}$ визначає зсув хвильового вектора конденсації м'яких оптичних фононів параелектричної фази від $q=0$ в сульфідній сполуці до $q>0$ в селенідній сполуці. Така зміна характеру динамічної нестабільності пов'язана з виникненням неспівмірної фази в твердих розчинах $\mathrm{Sn}_{2} \mathrm{P}_{2}\left(\mathrm{Se}_{x} \mathrm{~S}_{1-x}\right)_{6}$ при $x>0.28$. Виявлена можливість “двомодової" нестабільності в околі точки Ліфшиця - тут моделюється конденсація м'якої оптичної моди при $q \approx 0$ та змішаних оптичних та поперечних акустичних фононів при $q>0$, що потребує подальших експериментальних і теоретичних досліджень.
\end{abstract}

Ключові слова: динаміка ґратки, модель поляризованих іонів, сегнетоелектричні фазові переходи, неспівмірна фаза

PACS: $63.20 . \mathrm{Dj}, 77.80 . \mathrm{Bh}$ 